\title{
Gender Differences in Burnout Among Endocrinologists in China
}

\begin{abstract}
Jing Wang ${ }^{1,2}$, Lufa Zhang ${ }^{1,2,3 *}$, Feng Jiang ${ }^{2,3}$, Yuanli Liu ${ }^{4}$, Mingxiao Wang ${ }^{5}$, Yinuo Wu ${ }^{6 *}$ and Yi-Lang Tang ${ }^{7,8}$

${ }^{1}$ China Institute for Urban Governance, Shanghai Jiao Tong University, Shanghai, China, ${ }^{2}$ School of International and Public Affairs, Shanghai Jiao Tong University, Shanghai, China, ${ }^{3}$ Institute of Healthy Yangtze River Delta, Shanghai Jiao Tong University, Shanghai, China, ${ }^{4}$ School of Health Policy and Management, Chinese Academy of Medical Sciences \& Peking Union Medical College, Beijing, China, ${ }^{5}$ Department of Cardiology, Emergency General Hospital, Beijing, China, ${ }^{6}$ Chinese Academy of Medical Sciences \& Peking Union Medical College, Beijing, China, ${ }^{7}$ Department of Psychiatry and Behavioral Sciences, Emory University, Atlanta, GA, United States, ${ }^{8}$ Atlanta VA Medical Center, Decatur, GA, United States
\end{abstract}

Objective: To survey the prevalence of burnout in a national sample of endocrinologists

OPEN ACCESS

Edited by: Khaled Trabelsi,

University of Sfax, Tunisia

Reviewed by: Nasr Chalghaf,

University of Sfax, Tunisia Cyrine H'Mida,

University of Sfax, Tunisia Yousri Elghoul,

University of Sfax, Tunisia

*Correspondence:

Lufa Zhang

zhanglf@sjtu.edu.cn

Yinuo Wu

wuyinuo_pumc@163.com

Specialty section:

This article was submitted to Health Psychology,

a section of the journal

Frontiers in Psychology

Received: 29 December 2021

Accepted: 07 February 2022

Published: 01 March 2022

Citation:

Wang J, Zhang L, Jiang F, Liu Y, Wang M, Wu Y and Tang Y-L (2022) Gender Differences in Burnout Among Endocrinologists in China.

Front. Psychol. 13:845188.

doi: 10.3389/fpsyg.2022.845188 in China and to examine its correlates, with a special focus on gender differences.

Methods: An anonymous online survey was conducted among endocrinologists in 31 provincial government-owned "People's Hospitals" of each province in mainland China. Demographic and work-related factors were collected from participants. The Maslach Burnout Inventory-Human Services Survey (MBI-HSS) was used to assess burnout, including emotional exhaustion (EE), depersonalization (DP), and reduced personal accomplishment (PA).

Results: A total of 711 endocrinologists $(72.1 \%$ were female and mean age was $39.63 \pm 8.51$ years old) completed the survey. Burnout was reported by $32.8 \%$ of the participants. There were no significant gender differences in the overall prevalence of burnout or EE, DP, and PA (all $p>0.05$ ). A multi-level linear regression revealed: (1) In male participants, PA was significantly associated with age $(\beta=0.03, p=0.003)$, DP was inversely associated with age $(\beta=-0.06, p=0.005)$, EE was significantly associated with shorter sleep duration ( $\beta=-0.25, p=0.006)$, and longer work hours $(\beta=0.01$, $p=0.016)$. (2) In females, PA was significantly associated with age $(\beta=0.01, p=0.038)$, EE and DP were both significantly associated with shorter sleep duration $(\beta=-0.19$, $p=0.001$; and $\beta=-0.15, p=0.011$, respectively). EE and DP were also associated with work hours ( $\beta=0.02, p<0.001$; and $\beta=0.01, p<0.001$, respectively).

Conclusion: Nearly one-third of endocrinologists in China experienced burnout. Although there were no significant gender differences in the prevalence of overall burnout or EE, DP, and PA scores, male and female participants differed in factors associated with EE, DP, and PA. Interventions need to be tailored to target different aspects in male and female endocrinologists and target different subgroups.

\footnotetext{
Keywords: gender differences, burnout, endocrinologists, associated factors, prevalence
} 


\section{INTRODUCTION}

The concept of burnout in healthcare professionals has been used to describe the emotional and psychological status related to job stress (Rotenstein et al., 2018). According to Maslach's foundational work in the 1980s, burnout generally has been defined as a combination of emotional exhaustion (EE), depersonalization (DP), and reduced personal accomplishment (PA) (West et al., 2018). Factors that have been shown to contribute to burnout include excessive workloads, long working hours, frequent call duties; and individual factors, such as poor coping strategies, perfectionism, educational debt, relationship status, sleep deprivation, etc. (Shanafelt et al., 2015; Patel et al., 2018; West et al., 2018; Hacimusalar et al., 2021; Lin et al., 2021). A series of studies have found that burnout in physicians was associated with increased medical errors, poor patient satisfaction, and decreased physicians' health and safety (Panagioti et al., 2018; Dyer, 2019; Hu et al., 2019; Wu et al., 2020). Therefore, it is essential to ascertain the prevalence and associated factors of burnout in physicians. However, the findings of existing studies have shown a wide range in burnout prevalence, likely due to assessment methods, different samples, and study quality (Rotenstein et al., 2018).

Endocrinologists have played a uniquely important role in the Chinese healthcare system, owing to a very high prevalence of diabetes and other related metabolic diseases (Li et al., 2020; Li Y. et al., 2021; Zhang L. et al., 2021). Like all healthcare professionals, endocrinologists are not immune to physician burnout and stress. According to the Medscape Endocrinologist Lifestyle, Happiness \& Burnout Report 2020, 46\% of endocrinologists in the United States reported burnout, which was higher than the overall level of all physicians (41\%) (Medscape, 2020). A previous study demonstrated that the overall burnout rate among physicians from Chinese general hospitals was 31.28\% (Wu et al., 2020), while the prevalence of burnout in Chinese endocrinologists is still unclear.

Gender difference in burnout has been an interest of research for the past two decades. Many early researchers argued that burnout is more of a female experience (Maslach et al., 2001). In healthcare settings, several studies showed significant gender differences in physician burnout prevalence and associated factors. A few studies found that female health workers had a higher risk of burning out (Aguwa et al., 2014; Granek et al., 2016; Eden et al., 2020; Loscalzo et al., 2021; McPeek-Hinz et al., 2021), and some suggested that educational level, socioeconomic status and working hours were associated with burnout in female physicians (Norlund et al., 2010). On the contrary, a few studies found no gender differences in physician burnout (Linzer et al., 2002; te Brake et al., 2003; Doraiswamy et al., 2021).

This study aimed to survey the prevalence of burnout in a national sample of endocrinologists in China and to examine its correlates, with a special focus on gender differences. We hypothesized that there would be gender differences in the rate of burnout, and in the association between burnout and correlates among Chinese endocrinologists.

\section{MATERIALS AND METHODS}

\section{Study Design and Participants}

A national cross-sectional survey was conducted from March 18 to 31,2019 . The study was a part of the China Healthcare Improvement Initiative, which was supported by the National Health Committee (Zhou et al., 2018). We purposely invited the "People's Hospital" of each province in mainland China, as they are the most prominent hospitals affiliated with each provincial government. All of them were general tertiary hospitals (National Health Commission of the People's Republic of China, 2020). Thirty-one hospitals participated, and all endocrinologists who were working in those hospitals at that time were invited to participate in the anonymous online survey. To reach all endocrinologists, we collaborated with the hospital administrators of these hospitals to organize the endocrinologists to participate in this survey. The weblink of the survey was delivered through WeChat, a popular social app in mainland China.

The research protocol was approved by the Ethics Committee of the Emergency General Hospital in Beijing. Each participant completed the consent form before they began the questionnaire.

\section{Measures}

Burnout was assessed using the 22-item Maslach Burnout Inventory-Human Services Survey (MBI-HSS)(Maslach and Jackson, 1986). This scale has been considered the gold standard tool for burnout measuring (Verweij et al., 2017). The Chinese version of MBI-HSS has been shown to have good reliability and validity (Li et al., 2003). The Cronbach's $\alpha$ was 0.96 in this study.

It consists of three subscales: EE-nine items; DP- five items; and reduced PA- eight items. Each item was scored on a 7-point Likert scale, ranging from 0 (stands for never) to 6 (stands for always). We defined overall burnout as EE score $\geq 27$ and/or DP score $\geq 10$, aligned with one of the most popular criteria (Rotenstein et al., 2018). The Cronbach's $\alpha$ was 0.91 for EE, 0.79 for DP, and 0.89 for PA, respectively.

Additionally, we collected the basic sociodemographic data (age, sex, marital status, education, number of children) and work-related factors, such as professional title (junior, middle, and senior), administration position (yes or no), working hours per week, night shifts per month, and sleep hours per day, based on literature review (te Brake et al., 2003; Norlund et al., 2010; Rotenstein et al., 2018).

\section{Data Analysis}

One-sample K-S test was used to detect the normality of obtained data. Descriptive analyses were used to describe the sample's socio-demographic, burnout symptoms, and workrelated factors.

Since there is no consensus on the diagnostic criteria for burnout syndromes, some suggested the three subscales should be treated as continuous measures (Rotenstein et al., 2018). We adopted this approach in our analysis. The Chi-square test examined the gender difference of burnout prevalence. The Kruskal-Wallis test or Pearson correlation analysis was 
TABLE 1 | Basic Characteristics of 711 endocrinologists in China.

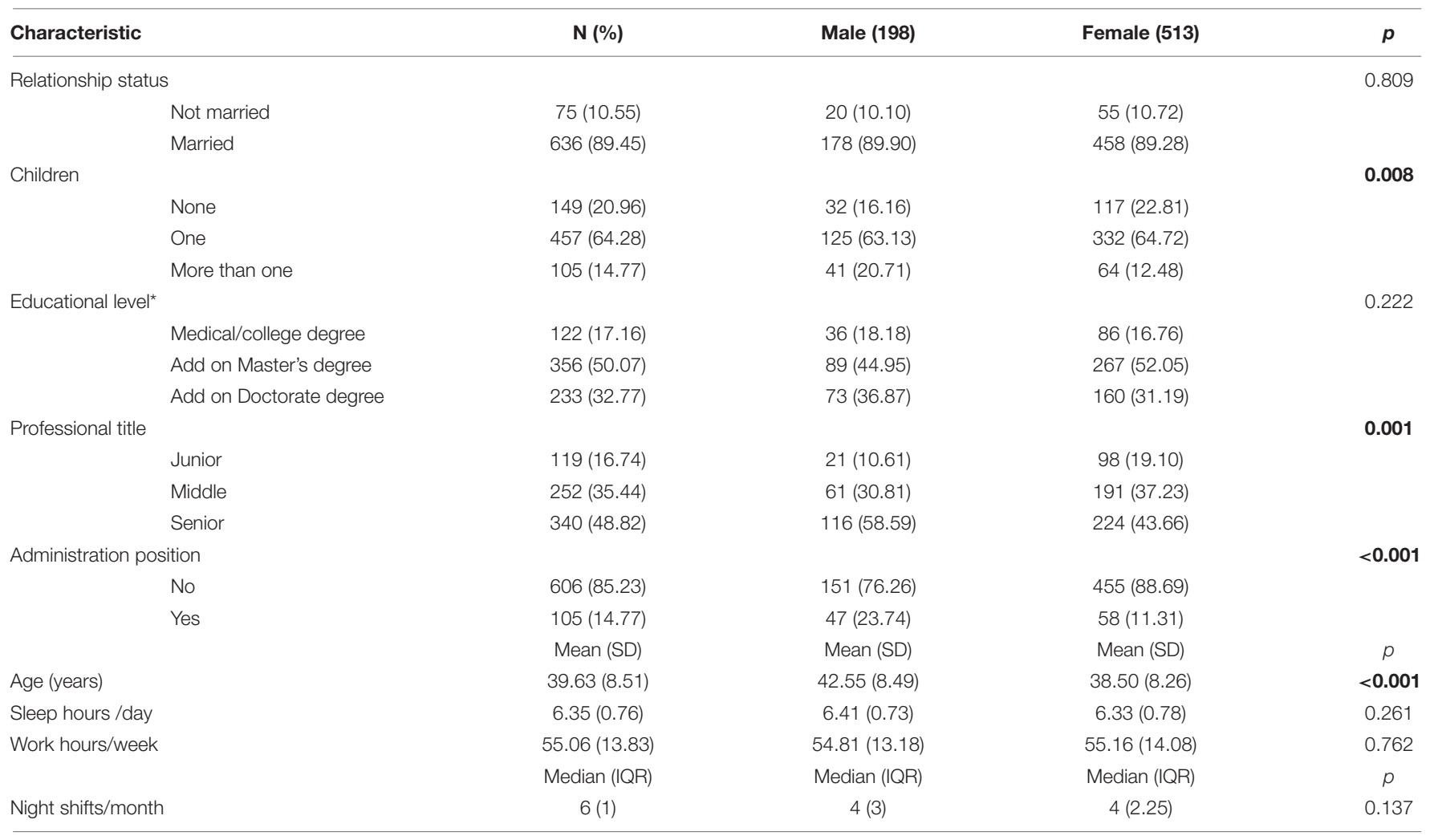

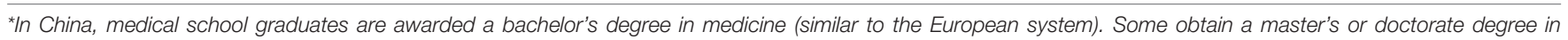
addition to their medical degree. Bold value for $p<0.05$.

conducted to test the correlation between related factors and EE, DP, and PA in male and female participants. After that, significant factors were involved in further regression analysis. As all endocrinologists nested in hospitals, multilevel linear regression analyses were conducted to identify independent factors associated with EE, DP, PA in male and female samples, respectively.

We performed all statistical analyses using the STATA software version 16.0 (Stata Corporation, College Station, TX, United States), with the significance level at the $p$-value of 0.05 (two-tailed).

\section{RESULTS}

\section{Sample Characteristics}

In total, all endocrinologists $(N=879)$ nested in these 31 hospitals were invited to respond to this survey, and 711 endocrinologists (response rate $=80.89 \%)$ completed the questionnaire. Table 1 shows the detailed information of their sociodemographic characteristics, job-related factors, and gender differences.

According to the Labor Law of China, workers should work no more than $44 \mathrm{~h}$ per week (Standing Committee of National People's Congress, 2019). However, nearly four-fifths (79.3\%) of the endocrinologists in our sample reported working more than $44 \mathrm{~h}$ per week, with no significant gender difference ( 79.8 in males vs. $79.1 \%$ in females, $p=0.847$ ).
The overall prevalence of burnout was $32.7 \%$ in this sample, again with no significant gender difference $34.3 \%$ in males and $32.2 \%$ in females, $p=0.579)$. There were no gender differences in EE, DP, PA scores either (all $p>0.05$ ) (Table 2).

Univariate analyses showed that professional title was associated with EE, DP in males, and DP in females; administration position was only associated with PA in females. Age, sleep duration, work hours, and the number of night shifts was associated with some of the EE, DP, and DP scores among endocrinologists (Table 3).

Furthermore, EE, DP, and DP scores were transformed into the standard normal distribution ( $\mathrm{Z}$ scores). In multilevel

TABLE 2 | Burnout in male $(N=198)$ and female $(N=513)$ endocrinologists in China.

\begin{tabular}{lcccc}
\hline & Total & Male & Female & p \\
\hline & $\begin{array}{c}\text { Mean } \\
\text { (Median, IQR) }\end{array}$ & $\begin{array}{c}\text { Mean } \\
\text { (Median, IQR) }\end{array}$ & $\begin{array}{c}\text { Mean } \\
\text { (Median, IQR) }\end{array}$ & \\
\hline EE & $16.71(15,15)$ & $15.91(14.5,14)$ & $17.02(15,14)$ & $0.249^{a}$ \\
DP & $7.29(6,7)$ & $7.24(6,7)$ & $7.30(6,7)$ & $0.875^{a}$ \\
PA & $32.24(33,17)$ & $31.80(33,19)$ & $32.41(34,16)$ & $0.670^{a}$ \\
& $\mathrm{~N}(\%)$ & $\mathrm{N}(\%)$ & $\mathrm{N}(\%)$ & \\
Burnout & $233(32.77 \%)$ & $68(34.34 \%)$ & $165(32.16 \%)$ & $0.579^{\mathrm{b}}$
\end{tabular}

${ }^{a}$ Kruskal-Wallis test.

${ }^{b}$ Chi square test. 
TABLE 3 | Univariate analyses of factors associated with burnout in 711 endocrinologists in China.

\begin{tabular}{|c|c|c|c|c|c|c|c|c|c|c|c|c|}
\hline \multirow[t]{3}{*}{ Variable } & \multicolumn{6}{|c|}{ Male } & \multicolumn{6}{|c|}{ Female } \\
\hline & \multicolumn{2}{|l|}{ EE } & \multicolumn{2}{|l|}{ DP } & \multicolumn{2}{|l|}{ PA } & \multicolumn{2}{|l|}{ EE } & \multicolumn{2}{|l|}{ DP } & \multicolumn{2}{|l|}{ PA } \\
\hline & Median (IQR) & $p$ & Median (IQR) & $p$ & Median (IQR) & $p$ & Median (IQR) & $p$ & Median (IQR) & $p$ & Median (IQR) & $p$ \\
\hline Relationship status & & 0.209 & & 0.171 & & 0.915 & & 0.848 & & 0.748 & & 0.883 \\
\hline Not married & $17.5(15)$ & & $7.5(7.5)$ & & $34(8.5)$ & & $14(14)$ & & $6(7)$ & & $33(13)$ & \\
\hline Married & $14(14)$ & & $6(7)$ & & $32(19)$ & & $15(14)$ & & $6(7)$ & & $34(16)$ & \\
\hline Children & & 0.251 & & 0.352 & & 0.404 & & 0.643 & & 0.255 & & 0.457 \\
\hline None & $19(16)$ & & $7(7.5)$ & & $32.5(17)$ & & $15(15)$ & & $6(6)$ & & $35(14)$ & \\
\hline One & $13(14)$ & & $6(7)$ & & $34(18)$ & & $15(15)$ & & $6(7)$ & & $32.5(17)$ & \\
\hline More than one & $15(12)$ & & $5(7)$ & & $30(22)$ & & $14(12)$ & & $5(7.5)$ & & $36(17.5)$ & \\
\hline Educational level & & 0.396 & & 0.231 & & 0.715 & & 0.086 & & 0.558 & & 0.524 \\
\hline Medical/college degree & $12(12)$ & & $4(7)$ & & $31.5(18)$ & & $13(13)$ & & $6(6)$ & & 34 (19) & \\
\hline Add on Master's degree & $15(16)$ & & $6(7)$ & & $33(16)$ & & $16(16)$ & & $6(7)$ & & $32(16)$ & \\
\hline Add on Doctorate degree & $14(14)$ & & $6(8)$ & & $34(18)$ & & $13(14)$ & & $6(7)$ & & $36(17)$ & \\
\hline Professional title & & 0.007 & & 0.007 & & 0.103 & & 0.256 & & 0.027 & & 0.657 \\
\hline Junior & $22(8)$ & & $10(7)$ & & $29(14)$ & & $14(15)$ & & $6(5)$ & & $34(16)$ & \\
\hline Middle & $16(19)$ & & $5(7)$ & & $33(18)$ & & $16(20)$ & & $7(9)$ & & $32(16)$ & \\
\hline Senior & $12(14)$ & & $6(7)$ & & $33(18.5)$ & & $14(11.5)$ & & $5(6)$ & & $35(17.5)$ & \\
\hline Administration position & & 0.125 & & 0.489 & & 0.908 & & 0.143 & & 0.248 & & 0.020 \\
\hline No & $15(16)$ & & $6(7)$ & & $33(18)$ & & $15(15)$ & & $6(7)$ & & $33(16)$ & \\
\hline Yes & $12(14)$ & & $6(7)$ & & $31(20)$ & & $13(13)$ & & $5(5)$ & & $39.5(17)$ & \\
\hline & $r$ & $p$ & $r$ & $p$ & $r$ & $p$ & $r$ & $p$ & $r$ & $p$ & $r$ & $p$ \\
\hline Age (years) & -0.27 & $<0.001$ & -0.27 & $<0.001$ & 0.21 & 0.003 & -0.06 & 0.203 & -0.11 & 0.014 & 0.12 & $<0.001$ \\
\hline Sleep hours /day & -0.18 & 0.009 & -0.04 & 0.556 & -0.07 & 0.341 & -0.20 & $<0.001$ & -0.13 & 0.003 & 0.06 & 0.161 \\
\hline Work hours/week & 0.26 & $<0.001$ & 0.15 & 0.030 & -0.07 & 0.300 & 0.31 & $<0.001$ & 0.25 & $<0.001$ & -0.03 & 0.494 \\
\hline Night shifts/month & 0.16 & 0.024 & 0.13 & 0.061 & -0.14 & 0.054 & 0.15 & $<0.001$ & 0.09 & 0.049 & -0.05 & 0.219 \\
\hline
\end{tabular}

TABLE 4 | Multilevel analysis of associated factors for burnout among 198 male endocrinologists.

\begin{tabular}{|c|c|c|c|c|c|c|c|c|c|c|c|c|}
\hline \multirow[t]{2}{*}{ Variable } & \multicolumn{4}{|c|}{$E^{*}$} & \multicolumn{4}{|c|}{ DP* } & \multicolumn{4}{|c|}{ PA $^{*}$} \\
\hline & $\beta$ & $\begin{array}{l}95 \% \mathrm{Cl} \\
\text { (Lower) }\end{array}$ & $\begin{array}{l}95 \% \mathrm{Cl} \\
\text { (Upper) }\end{array}$ & $p$ & $\beta$ & $\begin{array}{l}95 \% \mathrm{Cl} \\
\text { (Lower) }\end{array}$ & $\begin{array}{l}95 \% \mathrm{Cl} \\
\text { (Upper) }\end{array}$ & $p$ & $\beta$ & $\begin{array}{l}95 \% \mathrm{Cl} \\
\text { (Lower) }\end{array}$ & $\begin{array}{l}95 \% \mathrm{Cl} \\
\text { (Upper) }\end{array}$ & $p$ \\
\hline Age (years) & -0.02 & -0.05 & 0.00 & 0.059 & -0.03 & -0.06 & -0.01 & 0.005 & 0.03 & 0.01 & 0.04 & 0.003 \\
\hline Sleep hours /day & -0.25 & -0.42 & -0.07 & 0.006 & - & - & - & - & - & - & - & - \\
\hline Work hours/week & 0.01 & 0.00 & 0.02 & 0.016 & 0.01 & 0.00 & 0.02 & 0.256 & - & - & - & - \\
\hline Night shifts/month & 0.01 & -0.05 & 0.06 & 0.765 & - & - & - & - & - & - & - & - \\
\hline \multicolumn{13}{|c|}{ Professional title (ref. Junior) } \\
\hline Middle & -0.18 & -0.65 & 0.30 & 0.465 & -0.37 & -0.86 & 0.11 & 0.130 & - & - & - & - \\
\hline Senior & -0.12 & -0.67 & 0.44 & 0.680 & -0.13 & -0.70 & 0.44 & 0.650 & - & - & - & - \\
\hline
\end{tabular}

*Transformed into standardized normal variate.

Bold value for $p<0.05$.

linear regression analysis for male and female endocrinologists, standardized EE, DP, and DP scores were used as dependent variables, while the significant variables identified in univariate analyses were enrolled as independent variables. Table 4 demonstrates that shorter sleep duration was significantly associated with $\mathrm{EE}$ in males $(\beta=-0.25, p=0.006)$, while work hours were significantly associated with male $\operatorname{EE~}(\beta=0.01$, $p=0.016)$. Additionally, age was significantly associated with male PA ( $\beta=0.03, p=0.003)$, but was inversely related to male $\mathrm{DP}(\beta=-0.06, p=0.005)$.

Table 5 shows that shorter sleep duration was associated with female $\operatorname{EE}(\beta=-0.19, p=0.001)$ and $\mathrm{DP}(\beta=-0.15, p=0.011)$.
Work hours were significantly associated with $\mathrm{EE}(\beta=0.02$, $p<0.001)$ and DP $(\beta=0.01, p<0.001)$ in females. Age was also significantly associated with PA in females $(\beta=0.01, p=0.038)$.

\section{DISCUSSION}

This study was one of the first to survey the prevalence of burnout and the associated factors among Chinese endocrinologists. Our main findings include: (1) nearly one-third of participants reported burnout, and there was no significant gender difference in the overall prevalence of burnout; (2) a younger age was 
TABLE 5 | Multilevel analysis of associated factors for burnout among 513 female endocrinologists.

\begin{tabular}{|c|c|c|c|c|c|c|c|c|c|c|c|c|}
\hline \multirow[t]{2}{*}{ Variable } & \multicolumn{4}{|c|}{$\mathrm{EE}^{*}$} & \multicolumn{4}{|c|}{$D^{*}$} & \multicolumn{4}{|c|}{ PA $^{*}$} \\
\hline & $\beta$ & $\begin{array}{l}95 \% \mathrm{Cl} \\
\text { (Lower) }\end{array}$ & $\begin{array}{l}95 \% \text { Cl } \\
\text { (Upper) }\end{array}$ & $p$ & $\beta$ & $\begin{array}{l}95 \% \text { Cl } \\
\text { (Lower) }\end{array}$ & $\begin{array}{l}95 \% \text { Cl } \\
\text { (Upper) }\end{array}$ & $p$ & $\beta$ & $\begin{array}{l}95 \% \mathrm{Cl} \\
\text { (Lower) }\end{array}$ & $\begin{array}{l}95 \% \mathrm{Cl} \\
\text { (Upper) }\end{array}$ & $p$ \\
\hline Age (years) & - & - & - & - & -0.01 & -0.03 & 0.01 & 0.193 & 0.01 & 0.00 & 0.02 & 0.038 \\
\hline Sleep hours /day & -0.19 & -0.29 & -0.08 & 0.001 & -0.15 & -0.26 & -0.03 & 0.011 & - & - & - & - \\
\hline Work hours/week & 0.02 & 0.01 & 0.03 & $<0.001$ & 0.01 & 0.01 & 0.02 & $<0.001$ & - & - & - & - \\
\hline Night shifts/month & 0.02 & -0.01 & 0.05 & 0.177 & -0.01 & -0.04 & 0.03 & 0.723 & - & - & - & - \\
\hline \multicolumn{13}{|l|}{ Professional title (ref. Junior) } \\
\hline Middle & - & - & - & - & 0.24 & 0.00 & 0.49 & 0.054 & - & - & - & - \\
\hline Senior & - & - & - & - & 0.10 & -0.25 & 0.45 & 0.563 & - & - & - & - \\
\hline Administration position (ref. No) & - & - & - & - & - & - & - & - & 0.17 & -0.11 & 0.45 & 0.229 \\
\hline
\end{tabular}

*Transformed into standardized normal variate.

Bold value for $p<0.05$.

associated with DP in males, but not in females; and (3) DP was significantly associated with shorter sleep duration and longer work hours in females, but not in males. This suggested that there might be gender differences in the mechanism of burnout between burnout (DP) and related factors.

In this study, we found that age was an independent factor associated with PA, while sleep hours and work hours were significantly associated with EE among male and female endocrinologists, which is in concordance with previous studies (West et al., 2018; Hacimusalar et al., 2021; Lin et al., 2021).

Our finding that there were no significant gender differences in the overall prevalence of burnout is different from most previous studies. Numerous studies showed that female physicians had a higher prevalence of burnout from countries including America, China, Sweden, Nigeria, etc. (Norlund et al., 2010; Dyrbye et al., 2011; Aguwa et al., 2014; Granek et al., 2016; Huang et al., 2019; Eden et al., 2020; Gold et al., 2021; Lee et al., 2021; McPeek-Hinz et al., 2021). A few other studies reported only marginal gender differences in physician burnout prevalence (Linzer et al., 2002; te Brake et al., 2003; Śliwiński et al., 2014; El Ghaziri et al., 2019; Doraiswamy et al., 2021). The differences may be due to sampling, research settings, cultures, assessment methods for burnout, and variable cut-off valuesat least 142 unique burnout definitions or subscale criteria (Rotenstein et al., 2018). For example, previous studies have used the Shirom Melamed Burnout Questionnaire (Norlund et al., 2010), Freudenberger Burnout Scale (Aguwa et al., 2014), Mini-Z burnout scale (Gold et al., 2021), Utrechtse Burnout Schaal (te Brake et al., 2003), or Burnout Scale Inventory (Śliwiński et al., 2014). Others used one or two items to measure burnout (Granek et al., 2016; El Ghaziri et al., 2019; Eden et al., 2020; McPeek-Hinz et al., 2021). Huang et al. used a 7-point Likert scale for MBI-HSS, ranging from 1 to 7 , instead of 0 to 6 (Ma et al., 2019). Meanwhile, Lee et al. (2021) used a 5-point Likert scale for MBI. The methodological heterogeneity may contribute to the variations among the studies. Our findings are consistent with a meta-analysis, which included 183 studies of different populations. They showed that the commonly held belief that female employees are more likely to experience burnout is not supported by data (Purvanova and Muros, 2010).

Additionally, previous studies demonstrated that the gender differences might be attributed to job-related and situational life factors (te Brake et al., 2003; Norlund et al., 2010). Our study showed no significant gender differences in most job-related factors between male and female endocrinologists. This may help explain why the overall prevalence and subscales of burnout male and female endocrinologists were comparable.

Depersonalization, which is defined as "a negative attitude toward customers and clients, a personal detachment, or loss of ideals," is generally believed to result from low job satisfaction or poor work-life balance (Maslach, 1993). Some researchers suggested resilience and coping strategies play an important role in affecting DP (Chong et al., 2021; Di Giuseppe et al., 2021; Di Trani et al., 2021; Li P. et al., 2021; Nituica et al., 2021; Perry et al., 2021). Studies also showed gender differences in coping strategies and resilience (Gargiulo et al., 2021; Reisch et al., 2021; Yan et al., 2021; Zhang X. et al., 2021), and this could partially explain the gender differences regarding the differential associations between work hours and sleep duration and DP (Di Giuseppe et al., 2021). As the etiology and mechanism of burnout remain elusive, these findings would help understand the pathogenesis of physician burnout. In the meantime, hospital management and healthcare policymakers need to pay more attention to short sleep duration and long work hours among female physicians to reduce DP or burnout.

The present study has a few limitations. First, the findings were based on a cross-sectional survey, and the nature of the design makes it difficult to infer causality for most factors. Second, the study data obtained may have recall bias, as is inherent in self-report questionnaire studies. Third, as the sample was only from tertiary public hospitals in China, the generalizability of the study conclusions may be limited. Finally, some important information related to burnout, such as personality and resilience, were not collected.

\section{CONCLUSION}

In a large national sample, we found that nearly one-third of endocrinologists experienced burnout and the subscales in the sample. Although we did not find gender differences in the overall prevalence of burnout in the sample, we found in male and female participants that the associated factors 
were different, which indicated the mechanism of burnout in males and females might be different. This suggests that when developing interventions, hospital management should consider gender differences, and pay close attention to various aspects and target different subgroups, such as ensuring enough sleep duration and shortening work hours for female endocrinologists.

\section{DATA AVAILABILITY STATEMENT}

The original contributions presented in the study are included in the article/supplementary material, further inquiries can be directed to the corresponding authors.

\section{ETHICS STATEMENT}

The studies involving human participants were reviewed and approved by the Ethics Committee of the Emergency General

\section{REFERENCES}

Aguwa, E. N., Nduka, I., and Arinze-Onyia, S. U. (2014). Assessment of burnout among health workers and bankers in Aba south local government area, Abia state, south east nigeria. Niger. J. Clin. Pract. 17, 296-302. doi: 10.4103/11193077.130229

Chong, J. J., Tan, Y. Z., Chew, L. S. T., Tan, K. H., and Wang, A. (2021). Burnout and resilience among pharmacy technicians: a singapore study. J. Am. Pharm. Assoc. 2003:13. doi: 10.1016/j.japh.2021.09.013

Di Giuseppe, M., Nepa, G., Prout, T. A., Albertini, F., Marcelli, S., Orrù, G., et al. (2021). Stress, burnout, and resilience among healthcare workers during the COVID-19 emergency: the role of defense mechanisms. Int. J. Environ. Res. Public Health 18:258. doi: 10.3390/ijerph18105258

Di Trani, M., Mariani, R., Ferri, R., De Berardinis, D., and Frigo, M. G. (2021). From resilience to burnout in healthcare workers during the COVID-19 emergency: the role of the ability to tolerate uncertainty. Front. Psychol. 12:646435. doi: 10.3389/fpsyg.2021.646435

Doraiswamy, S., Chaabna, K., Jithesh, A., Mamtani, R., and Cheema, S. (2021). Physician burnout in the eastern mediterranean region: influence of gender and related factors - systematic review and meta-analysis. J. Glob. Health 11:04043. doi: 10.7189/jogh.11.04043

Dyer, O. (2019). Physician burnout costs US $\$ 4.6$ bn a year, study finds. BMJ 365:12361. doi: 10.1136/bmj.12361

Dyrbye, L. N., Shanafelt, T. D., Balch, C. M., Satele, D., Sloan, J., and Freischlag, J. (2011). Relationship between work-home conflicts and burnout among American surgeons: a comparison by sex. Arch. Surg. 146, 211-217. doi: 10. 1001/archsurg.2010.310

Eden, A. R., Jabbarpour, Y., Morgan, Z. J., Dai, M., Coffman, M., and Bazemore, A. (2020). Gender differences in personal and organizational mechanisms to address burnout among family physicians. J. Am. Board Fam. Med. 33, 446-451. doi: 10.3122/jabfm.2020.03.190344

El Ghaziri, M., Dugan, A. G., Zhang, Y., Gore, R., and Castro, M. E. (2019). Sex and gender role differences in occupational exposures and work outcomes among registered nurses in correctional settings. Ann. Work Exp. Health 63, 568-582. doi: 10.1093/annweh/wxz018

Gargiulo, A. T., Peterson, L. M., and Grafe, L. A. (2021). Stress, coping, resilience, and sleep during the COVID-19 pandemic: a representative survey study of US adults. Brain Behav. 11:e2384. doi: 10.1002/brb3.2384

Gold, K. J., Kuznia, A. L., Laurie, A. R., and Williams, C. B. (2021). Gender differences in stress and burnout: department survey of academic family physicians. J. Gen. Intern. Med. 36, 1811-1813. doi: 10.1007/s11606-020-0 6287-y

Granek, L., Krzyzanowska, M. K., Nakash, O., Cohen, M., Ariad, S., Barbera, L., et al. (2016). Gender differences in the effect of grief reactions and burnout
Hospital in Beijing. The patients/participants provided their written informed consent to participate in this study.

\section{AUTHOR CONTRIBUTIONS}

YL and YW made substantial contributions to the study design. MW and YW collected data. JW and FJ analyzed the data. JW, LZ, and FJ interpreted the analysis results and completed the manuscripts. Y-LT contributed to data interpretation, presentation, and critical revision of the manuscript. All authors have read and approved the published version of the manuscript.

\section{ACKNOWLEDGMENTS}

The participating institutions and physicians are thanked for their contribution.

on emotional distress among clinical oncologists. Cancer 122, 3705-3714. doi: 10.1002/cncr.30236

Hacimusalar, Y., Misir, E., Civan Kahve, A., Demir Hacimusalar, G., Guclu, M. A., and Karaaslan, O. (2021). The effects of working and living conditions of physicians on burnout level and sleep quality. Med. Lav. 112, 346-359. doi: 10.23749/mdl.v112i5.11268

Hu, Y. Y., Ellis, R. J., Hewitt, D. B., Yang, A. D., Cheung, E. O., Moskowitz, J. T., et al. (2019). Discrimination, abuse, harassment, and burnout in surgical residency training. N Engl. J. Med. 381, 1741-1752. doi: 10.1056/ NEJMsa1903759

Huang, S. L., Li, R. H., Fang, S. Y., and Tang, F. C. (2019). Well-being: its relationship with work-to-family conflict and burnout among males and females. Int. J. Environ. Res. Public Health 16:291. doi: 10.3390/ijerph161 32291

Lee, S. J., Jung, S. I., Kim, M. G., Park, E., Kim, A. R., Kim, C. H., et al. (2021). The influencing factors of gender differences on mental burdens in young physiotherapists and occupational therapist. Int. J. Environ. Res. Public Health 18:858. doi: 10.3390/ijerph18062858

Li, C. P., Shi, K., Luo, Z. X., Li, L., and Yang, R. (2003). An investigation on job burnout of doctor and nurse. Chin. J. Clin. Psychol. 11, 170-172.

Li, P., Kuang, H., and Tan, H. (2021). The occurrence of post-traumatic stress disorder (PTSD), job burnout and its influencing factors among ICU nurses. Am. J. Transl. Res. 13, 8302-8308.

Li, Y., Guo, C., and Cao, Y. (2021). Secular incidence trends and effect of population aging on mortality due to type 1 and type 2 diabetes mellitus in China from 1990 to 2019: findings from the global burden of disease study 2019. BMJ Open Diabetes Res. Care 9:529. doi: 10.1136/bmjdrc-2021-0 02529

Li, Y., Teng, D., Shi, X., Qin, G., Qin, Y., Quan, H., et al. (2020). Prevalence of diabetes recorded in mainland China using 2018 diagnostic criteria from the american diabetes association: national cross sectional study. BMJ 369:m997. doi: 10.1136/bmj.m997

Lin, R. T., Lin, Y. T., Hsia, Y. F., and Kuo, C. C. (2021). Long working hours and burnout in health care workers: non-linear dose-response relationship and the effect mediated by sleeping hours-a cross-sectional study. J. Occup. Health 63:e12228. doi: 10.1002/1348-9585.12228

Linzer, M., Mcmurray, J. E., Visser, M. R., Oort, F. J., Smets, E., and De Haes, H. C. (2002). Sex differences in physician burnout in the united states and the netherlands. J. Am. Med. Womens Assoc 57, 191-193.

Loscalzo, Y., Marucci, S., Garofalo, P., Attanasio, R., Lisco, G., De Geronimo, V., et al. (2021). Assessment of burnout levels before and during COVID19 pandemic: a web-based survey by the (Italian) association of medical endocrinologists (AME). Endocr. Metab. Immune Dis. Drug Targets 21, 2238 2252. doi: $10.2174 / 1871530321666210720123336$ 
Ma, S., Huang, Y., Yang, Y., Ma, Y., Zhou, T., Zhao, H., et al. (2019). Prevalence of burnout and career satisfaction among oncologists in china: a national survey. Oncologist 24, e480-e489. doi: 10.1634/theoncologist.2018-0249

Maslach, C. (1993). "Burnout: a multidimensional perspective," in Professional Burnout: Recent Developments in Theory and Research, Schaufeli Wb, eds C. Maslach and T. Marek (Washington, DC: Taylor \& Francis).

Maslach, C., Schaufeli, W. B., and Leiter, M. P. (2001). Job burnout. Annu. Rev. Psychol. 52, 397-422. doi: 10.1146/annurev.psych.52.1.397

Maslach, C. J., and Jackson, S. E. (1986). Maslach Burnout Inventory Manual, 2nd Edn. Palo Alto, CA: Consulting Psychologists Press.

McPeek-Hinz, E., Boazak, M., Sexton, J. B., Adair, K. C., West, V., Goldstein, B. A., et al. (2021). Clinician burnout associated with sex, clinician type, work culture, and use of electronic health records. JAMA Net. Open 4:e215686. doi: 10.1001/jamanetworkopen.2021.5686

Medscape (2020). Medscape Endocrinologist Lifestyle, Happiness \& Burnout Report 2020. Available online at: https://www.medscape.com/slideshow/2020-lifestyleendocrinologist-6012494\#4 (accessed December 11, 2021)

National Health Commission of the People's Republic of China (2020). China Health Statistical Yearbook. Beijing: Press of Peking Union Medical College.

Nituica, C., Bota, O. A., Blebea, J., Cheng, C. I., and Slotman, G. J. (2021). Factors influencing resilience and burnout among resident physicians - a national survey. BMC Med. Educ. 21:514. doi: 10.1186/s12909-021-02950-y

Norlund, S., Reuterwall, C., Höög, J., Lindahl, B., Janlert, U., and Birgander, L. S. (2010). Burnout, working conditions and gender-results from the northern Sweden MONICA study. BMC Public Health 10:326. doi: 10.1186/1471-245810-326

Panagioti, M., Geraghty, K., Johnson, J., Zhou, A., Panagopoulou, E., ChewGraham, C., et al. (2018). Association between physician burnout and patient safety, professionalism, and patient satisfaction: a systematic review and metaanalysis. JAMA Int. Med. 178, 1317-1330. doi: 10.1001/jamainternmed.2018. 3713

Patel, R. S., Bachu, R., Adikey, A., Malik, M., and Shah, M. (2018). Factors related to physician burnout and its consequences: a review. Behav Sci. 8:98. doi: 10 . 3390/bs8110098

Perry, H., Naud, S., Fishman, M. D. C., and Slanetz, P. J. (2021). Longitudinal resilience and burnout in radiology residents. J. Am. Coll. Radiol. 18, 639-646. doi: 10.1016/j.jacr.2021.01.022

Purvanova, R. K., and Muros, R. P. (2010). Gender differences in burnout: a meta-analysis. J. Vocational Behav. 77, 168-185. doi: 10.1016/j.jvb.2010.04.006

Reisch, T., Heiler, G., Hurt, J., Klimek, P., Hanbury, A., and Thurner, S. (2021). Behavioral gender differences are reinforced during the COVID-19 crisis. Sci. Rep. 11:19241. doi: 10.1038/s41598-021-97394-1

Rotenstein, L. S., Torre, M., Ramos, M. A., Rosales, R. C., Guille, C., Sen, S., et al. (2018). Prevalence of burnout among physicians: a systematic review. JAMA 320, 1131-1150. doi: 10.1001/jama.2018.12777

Shanafelt, T. D., Hasan, O., Dyrbye, L. N., Sinsky, C., Satele, D., Sloan, J., et al. (2015). Changes in burnout and satisfaction with work-life balance in physicians and the general US working population between 2011 and 2014. Mayo Clin. Proc. 90, 1600-1613. doi: 10.1016/j.mayocp.2015. 08.023

Śliwiński, Z., Starczyńska, M., Kotela, I., Kowalski, T., Kryś-Noszczyk, K., LietzKijak, D., et al. (2014). Life satisfaction and risk of burnout among men and women working as physiotherapists. Int. J. Occup. Med. Environ. Health 27, 400-412. doi: 10.2478/s13382-014-0266-8

Standing Committee of National People's Congress (2019). Labor Law of the People's Republic of China. Beijing: National People's Congress of China.

te Brake, H., Bloemendal, E., and Hoogstraten, J. (2003). Gender differences in burnout among dutch dentists. Commun. Dent Oral Epidemiol. 31, 321-327. doi: 10.1034/j.1600-0528.2003.t01-1-00010.x

Verweij, H., Van Der Heijden, F., Van Hooff, M. L. M., Prins, J. T., LagroJanssen, A. L. M., Van Ravesteijn, H., et al. (2017). The contribution of work characteristics, home characteristics and gender to burnout in medical residents. Adv. Health Sci. Educ. Theory Pract. 22, 803-818. doi: 10.1007/ s10459-016-9710-9

West, C. P., Dyrbye, L. N., and Shanafelt, T. D. (2018). Physician burnout: contributors, consequences and solutions. J. Int. Med. 283, 516-529. doi: 10. 1111/joim.12752

Wu, Y., Jiang, F., Ma, J., Tang, Y. L., Wang, M., and Liu, Y. (2020). Experience of medical disputes, medical disturbances, verbal and physical violence, and burnout among physicians in china. Front. Psychol. 11:556517. doi: 10.3389/ fpsyg.2020.556517

Yan, S., Xu, R., Stratton, T. D., Kavcic, V., Luo, D., Hou, F., et al. (2021). Sex differences and psychological stress: responses to the COVID-19 pandemic in China. BMC Public Health 21:79. doi: 10.1186/s12889-020-10085-w

Zhang, L., Chen, J., Zhang, J., Wu, W., Huang, K., Chen, R., et al. (2021). Regional disparities in obesity among a heterogeneous population of chinese children and adolescents. JAMA Netw Open 4:e2131040. doi: 10.1001/jamanetworkopen. 2021.31040

Zhang, X., Deng, X., Mo, Y., Li, Y., Song, X., and Li, H. (2021). Relationship between infertility-related stress and resilience with posttraumatic growth in infertile couples: gender differences and dyadic interaction. Hum. Reprod 36, 1862-1870. doi: 10.1093/humrep/deab096

Zhou, H., Han, X., Zhang, J., Sun, J., Hu, L., Hu, G., et al. (2018). Job satisfaction and associated factors among medical staff in tertiary public hospitals: results from a national cross-sectional survey in china. Int. J. Environ. Res. Public Health 15:1528. doi: 10.3390/ijerph15071528

Conflict of Interest: The authors declare that the research was conducted in the absence of any commercial or financial relationships that could be construed as a potential conflict of interest.

Publisher's Note: All claims expressed in this article are solely those of the authors and do not necessarily represent those of their affiliated organizations, or those of the publisher, the editors and the reviewers. Any product that may be evaluated in this article, or claim that may be made by its manufacturer, is not guaranteed or endorsed by the publisher.

Copyright (c) 2022 Wang, Zhang, Jiang, Liu, Wang, Wu and Tang. This is an openaccess article distributed under the terms of the Creative Commons Attribution License (CC BY). The use, distribution or reproduction in other forums is permitted, provided the original author(s) and the copyright owner(s) are credited and that the original publication in this journal is cited, in accordance with accepted academic practice. No use, distribution or reproduction is permitted which does not comply with these terms. 